Open Access

\title{
Cryptic diversity in Hipposideros commersoni sensu stricto (Chiroptera: Hipposideridae) in the western portion of Madagascar
}

Andrinajoro R. Rakotoarivelo ${ }^{1,2,5^{*}}$, Sandi Willows-Munro ${ }^{1}$, M. Corrie Schoeman³ ${ }^{3}$ Jennifer M. Lamb ${ }^{3}$ and Steven M. Goodman ${ }^{2,4}$

\begin{abstract}
Background: The Commerson's leaf-nosed bat, Hipposideros commersoni sensu stricto, is endemic to Madagascar and is relatively common in the western portion of the island, where it is found in areas, including forested zones, from sea level to $1325 \mathrm{~m}$. A previous study on morphological patterns of geographic variation within the species highlighted the presence of two distinct morphotypes; larger individuals in the north portion of the island and smaller individuals in the south. The main aim of this study was to use a combination of craniodental morphology and molecular data (mitochondrial and nuclear) to test previous hypotheses based on morphology and clarify the evolutionary history of the species group.
\end{abstract}

Methods: We sequenced mitochondrial and nuclear genes from Hipposideros commersoni obtained from the western portion of Madagascar, and compared them with other African species as outgroups. We analyzed the sequence data using Maximum Likelihood and Bayesian phylogenetic inference. Divergence dates were estimated using Bayesian molecular clock approach. Variation in craniodental variables was also assessed from sequenced individuals.

Results: The molecular analyses suggest that $H$. commersoni is not monophyletic, with strong support for the presence of several independently evolving lineages. Two individuals amongst those sequenced from Isalo (south central) and Itampolo (southwest) form a separate clade (Clade A), distinct from other H. commersoni, and sister to continental African $H$. vittatus and $H$. gigas. Within the $H$. commersoni clade, the molecular data support two geographically distributed clades; one from the south (Clade B) and the other from the north (Clade C), which diverged approximately 3.38 million years ago. Morphometric data were consistent with the molecular analyses, suggesting a north-south break within H. commersoni. However, at some localities, animals from both clades occurred in sympatry and these individuals could not be differentiated based on external and craniodental measurements.

Conclusions: Using a combination of molecular and morphological characters, this study presents evidence of cryptic diversity in H. commersoni on Madagascar. Further fine-scale phylogeographic studies are needed to fully resolve the systematics of $\mathrm{H}$. commersoni. This study highlights the utility of the combined approach in employing both morphological and molecular data to provide insights into the evolutionary history of Malagasy population currently assigned to $\mathrm{H}$. commersoni.

Keywords: Dry forest, Phylogeny, Paraphyly, Evolutionary history, Systematics, Morphology

\footnotetext{
* Correspondence: andrinajoro@moov.mg

${ }^{1}$ School of Life Sciences, Pietermaritzburg Campus, Rabie Saunders Building,

University of Kwa-Zulu Natal, Pietermaritzburg 3209, South Africa

${ }^{2}$ Association Vahatra, BP 3972, Antananarivo 101, Madagascar

Full list of author information is available at the end of the article
}

\section{Biomed Central}

(C) 2015 Rakotoarivelo et al. Open Access This article is distributed under the terms of the Creative Commons Attribution 4.0 International License (http://creativecommons.org/licenses/by/4.0/), which permits unrestricted use, distribution, and reproduction in any medium, provided you give appropriate credit to the original author(s) and the source, provide a link to the Creative Commons license, and indicate if changes were made. The Creative Commons Public Domain Dedication waiver (http://creativecommons.org/publicdomain/zero/1.0/) applies to the data made available in this article, unless otherwise stated. 


\section{Background}

Members of the Family Hipposideridae, known as Old World leaf-nosed bats, are one of the most widespread and abundant groups of insectivorous bats and inhabit tropical and subtropical regions of Africa, the Middle East, Asia and Australia [1]. To a large extent, species within this genus have been defined based on their external and craniodental morphology. In a recent summary, 70 species of Hipposideros were recognized [1], subsequently numerous other taxa have been described (e.g. [2-5]) and the taxonomy of the group, predominantly at the species level, is far from resolved. As a tool to understand the evolutionary history of members of this genus, closely related species are often placed in morphological species groups (e.g., $[1,6])$. As currently delineated, the $H$. commersoni group includes the Afro-Malagasy taxa H. commersoni (É. Geoffroy, 1813), described from Madagascar, and $H$. thomensis (Bocage, 1891), $H$. gigas (Wagner, 1845) and $H$. vittatus (Peters, 1852), from continental Africa and offshore islands. The last-named three forms were previously considered subspecies of $H$. commersoni sensu lato, but were recently raised to species rank [1] based on reputed morphology and echolocation call differences [7-9]). As members of the $H$. commersoni group s.l. have to date not been the subject of a detailed phylogenetic study, it is unclear if these taxonomic changes reflect the evolutionary relationships within this portion of the genus or are examples of morphological convergence [10].

Hipposideros commersoni sensu stricto is a widespread endemic to Madagascar and can be found from sea level to $1325 \mathrm{~m}$, generally in forested zones [11]. Its diet (mostly Coleoptera) and activity in western Madagascar may change seasonally and may be related to possible intra-island movements [12-15]. On the basis of current information, Malagasy populations of $H$. commersoni demonstrate considerable geographic variation in morphological measurements and certain patterns cannot be explained by simple clines [16].

In this study, we examine genetic and morphological variation in $H$. commersoni using samples obtained from different areas of Madagascar within and outside dry forest formations, specifically the western half of the island, to explore aspects of their phylogenetic history and to help resolve the systematic relationships of the different morphotypes recovered by Ranivo and Goodman [16].

\section{Methods}

\section{Morphological and molecular sampling}

In this paper, reference to Hipposideros commersoni is restricted to Malagasy populations and, hence, sensu stricto. A total of $22 \mathrm{H}$. commersoni (20 females and two males) were included in the molecular portion of this study (Table 1). During the past two decades intensive bats survey were carried out by different researchers across Madagascar, but with a distinct bias towards the west, where there are often extensive cave systems used as day roost sites for Hipposideros. The collection of H. commersoni specimens and associated tissues were greatly biased in this context. This species is present in eastern part of Madagascar but only a few specimens were available. Morphological analyses were only conducted on the $20 \mathrm{fe}$ males. These samples come from collections made over the past 15 years from 11 localities across the western portion of Madagascar (Fig. 1). All voucher specimens are cataloged in the Field Museum of Natural History (FMNH) or Université d'Antananarivo, Département de Biologie Animale (UADBA). Samples used in the molecular study included the aforementioned material, as well as additional tissue samples of $H$. vittatus $(n=7)$ and $H$. gigas $(n=1)$, two morphologically similar species [17], from the FMNH and the American Museum of Natural History (AMNH) collections (Table 1, Fig. 1).

\section{DNA sequencing}

Genomic DNA was isolated using the NucleoSpin ${ }^{\odot}$ Tissue kit (Macherey-Nagel, Germany), following the manufacturers protocol for tissue samples. Two mitochondrial (mtDNA) and two nuclear intron (ncDNA) markers were amplified.

The cytochrome $b$ gene $(C y t b)$ was amplified using two sets of nested primers. The primers L14724AG (5'-ATG ATA TGA AAA ACC ATC GTT G-3'; [4]) and H15915 (5'-TCT CCA TTT CTG GTT TAC AAG AC-3'; [18]) were used to amplify a 1200 bp segment of $C y t b$. In specimens in which L14724AG and H15915 did not amplify, the primers JorF (5'-GAC CTT CCA ACT CCC TCA AGC AT-3'; designed for study) and H15553 (5'-TAG GCA AAT AGG AAA TAT CAT TCT GGT-3'; [18]) were used to amplify a smaller $700 \mathrm{bp}$ segment. The hypervariable portion of the control region (CR) of the mitochondrial genome was amplified in all specimens as a single fragment using primers P $\left(5^{\prime}-\mathrm{TCC}\right.$ TAC CAT CAG CAC CCA AAG C$\left.3^{\prime}\right)$ and E (5'-CCT GAA GTA GGA ACC AGA TG-3'; [19]). The $16^{\text {th }}$ intron of the signal transducer and activator of transcription 5A (STAT) was amplified using previously published primers (bSTATa 5'-GAA GAA ACA TCA CAA GCC CC-3', bSTATb 5'-AGA CCT CAT CCT TGG GCC-3'; $[20,21])$. The $5^{\text {th }}$ intron of the organic solute transporter subunit alpha gene (OSTA5) was amplified using the primers OSTA5F (5'-TGM WGG YCA TGG TGG AAG GCT TTG-3)' and OSTA5R (5'-AGA TGC CRT CRG GGA YGA GRA ACA-3'; [22]). The STAT marker was used based on the work of Eick et al. [20], who found high levels of intraspecific divergence for this marker in 58 bat species. Igea et al. [22] identified the intron OSTA5 to be an adequate marker for analyses of species delimitation, gene flow and genetic differentiation within two bat species. Cycle sequencing was performed using BigDye Chemistry (Version 3.1, Applied Biosystems, USA), and 
Table 1 Details of specimens included in the molecular analysis ( $n=22,20$ females and 2 males). The Hipposideros commersoni specimens are all from Madagascar; more precise details on collection localities are presented in Appendix 1

\begin{tabular}{|c|c|c|c|c|c|c|}
\hline \multirow[t]{2}{*}{ Species } & \multirow[t]{2}{*}{ Museum number } & \multicolumn{4}{|c|}{ GenBank numbers } & \multirow[t]{2}{*}{ Collection locality } \\
\hline & & $C R$ & Cyt b & bSTAT & OSTA5 & \\
\hline Hipposideros commersoni & FMNH 169707 & KT371749 & KT5838015 & KT583770 & KT437663 & Andrafiabe, Ankarana \\
\hline Hipposideros commersoni & FMNH 175777 & KT371750 & KT5838022 & KT583771 & KT437664 & Andranomavo, Namoroka \\
\hline Hipposideros commersoni & FMNH 175966 & KT371751 & KT5838023 & KT583772 & KT437665 & Menamaty, Isalo \\
\hline Hipposideros commersoni & FMNH175970 & KT371752 & KT5838011 & KT583773 & KT437666 & Berenty-Betsileo, Isalo \\
\hline Hipposideros commersoni & FMNH 176155 & KT371753 & KT5838024 & KT583774 & KT437667 & Ankiloaka, Mikea Forest \\
\hline Hipposideros commersoni & FMNH 177302 & KT371754 & KT5838025 & KT583775 & KT437668 & Ampijoroa \\
\hline Hipposideros commersoni & FMNH 178806 & KT371755 & KT5838016 & KT583776 & KT437669 & Bazaribe Cave, Analamerana \\
\hline Hipposideros commersoni & FMNH 178808 & KT371756 & KT5838017 & KT583777 & KT437670 & Bazaribe Cave, Analamerana \\
\hline Hipposideros commersoni & FMNH 178809 & KT371757 & KT5838018 & KT583778 & KT437671 & Bazaribe Cave, Analamerana \\
\hline Hipposideros commersoni & FMNH 178810 & KT371758 & KT5838019 & KT583779 & KT437672 & Bazaribe Cave, Analamerana \\
\hline Hipposideros commersoni & FMNH 178811 & KT371759 & KT5838020 & KT583780 & KT437673 & Bazaribe Cave, Analamerana \\
\hline Hipposideros commersoni & FMNH 178815 & KT371760 & KT5838021 & KT583781 & KT437674 & Bazaribe Cave, Analamerana \\
\hline Hipposideros commersoni & FMNH 178812 & KT371761 & KT5838026 & KT583782 & KT437675 & Bazaribe Cave, Analamerana \\
\hline Hipposideros commersoni & FMNH 183934 & KT371762 & KT5838027 & KT583783 & KT437676 & Mitoho Cave, Tsimanampetsotsa \\
\hline Hipposideros commersoni & FMNH 184170 & KT371763 & KT5838028 & KT583784 & KT437677 & Androimpano Cave, Itampolo \\
\hline Hipposideros commersoni & FMNH 184173 & KT371764 & KT5838010 & KT583785 & KT437678 & Androimpano Cave, Itampolo, \\
\hline Hipposideros commersoni & FMNH 184030 & KT371765 & KT5838012 & KT583786 & KT437679 & 4.2 km SE Marovaza, in cave \\
\hline Hipposideros commersoni & FMNH 183980 & KT371766 & KT5838013 & KT583787 & KT437680 & Ampitiliantsambo Forest, Montagne de Français \\
\hline Hipposideros commersoni & FMNH 217940 & KT371767 & KT5838031 & KT583788 & KT437681 & Ranohira, Isalo \\
\hline Hipposideros commersoni & UADBA 32987 & KT371768 & KT5838014 & KT583789 & KT437682 & Andrafiabe, Ankarana \\
\hline Hipposideros commersoni & FMNH 221308 & KT371769 & KT5838029 & KT583790 & KT437683 & Andrafiabe, Ankarana \\
\hline Hipposideros commersoni & UADBA32916 & KT371770 & KT5838030 & KT583791 & KT437684 & Anjohibe Cave, Antanamarina, \\
\hline Hipposideros vittatus & FMNH 192800 & KT371772 & KT583803 & KT583792 & KT437685 & Kasinji Region, Pemba Island, Tanzania \\
\hline Hipposideros vittatus & FMNH 192857 & KT371773 & KT583804 & KT583793 & KT437686 & Kasinji Region, Pemba Island, Tanzania \\
\hline Hipposideros vittatus & FMNH 192858 & KT371774 & KT583805 & KT583794 & KT437687 & Kasinji Region, Pemba Island, Tanzania \\
\hline Hipposideros vittatus & FMNH 192859 & KT371775 & KT583806 & KT583795 & KT437688 & Kasinji Region, Pemba Island, Tanzania \\
\hline Hipposideros vittatus & FMNH 192860 & KT371776 & KT583807 & KT583796 & KT437689 & Kasinji Region, Pemba Island, Tanzania \\
\hline Hipposideros vittatus & FMNH 192865 & KT371777 & KT583808 & KT583797 & - & Kasinji Region, Pemba Island, Tanzania \\
\hline Hipposideros vittatus & FMNH 192866 & KT371778 & KT583809 & KT583798 & KT437690 & Kasinji Region, Pemba Island, Tanzania \\
\hline Hipposideros gigas & AMNH 269871 & KT371748 & KT583801 & KT583799 & KT437691 & Dzanga Sangha Forest Reserve, Central African Republic \\
\hline Hipposideros vittatus & AMNH 269879 & KT371771 & KT583802 & KT583800 & KT437692 & Dzanga Sangha Forest Reserve, Central African Republic \\
\hline
\end{tabular}

Collection numbers are those assigned to each specimen by museums FMNH (Field Museum of Natural History), AMNH (American Museum of Natural History) and UADBA (Université d'Antananarivo, Département de Biologie Animale; - = missing data

products analyzed on a $3100 \mathrm{ABI}$ automated sequencer (Applied Biosystems). All heterozygous sites in the ncDNA were coded using the IUB code. All sequences were first aligned using ClustalW [23] as implemented in BioEdit [24], and thereafter manually to optimize homology. All new sequences were deposited in GenBank (Table 1).

\section{Sequence analyses}

The four markers (CR, Cyt b, STAT and OSTA5) were analyzed separately and then combined into a single data set. Gaps were treated as missing data. In addition, the markers were concatenated and analyzed according to origin of marker (mtDNA or nucDNA). The number of variable sites, number of parsimony informative sites and nucleotide frequencies were estimated for each data matrix in MEGA 6 [25].

Phylogenetic reconstruction was performed using both maximum likelihood (ML) and Bayesian (Bayes) approaches using the programs Garli 2.0 [26] and MrBayes 3.2 [27], respectively. The most appropriate substitution model for each gene $(\mathrm{CR}-\mathrm{HKY}+\mathrm{I}+\mathrm{G}, \mathrm{Cyt} b-\mathrm{HKY}+\mathrm{I}$, STAT - TIM1 + I, OSTA5 - TIM1ef + I) was selected using 


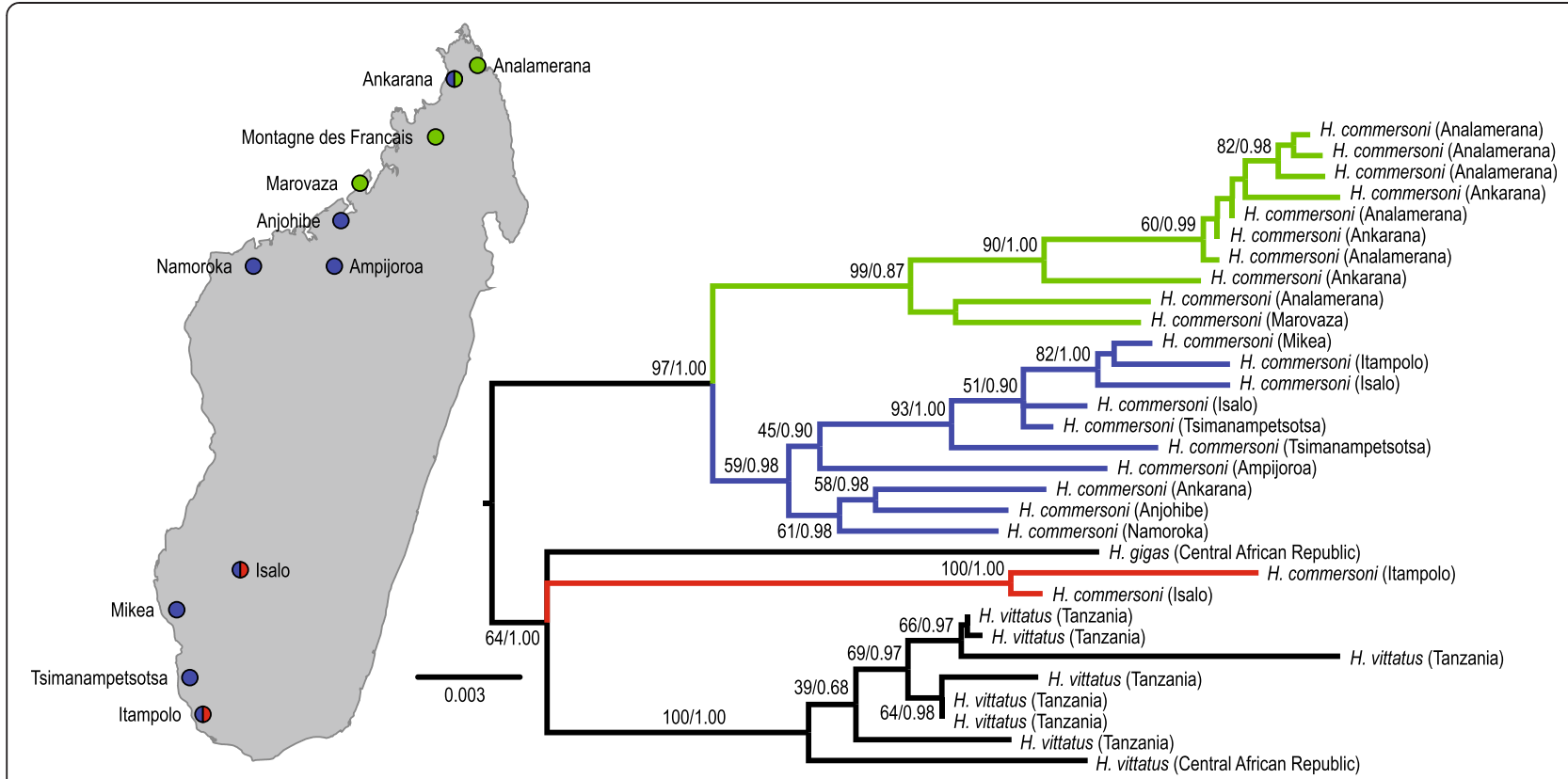

Fig. 1 Geographical distribution of Hipposideros commersoni specimens analysed in the present study (left). Localities are colour-coded according to the main phylogenetic lineages ( $r e d=C$ lade A, blue =Clade B, green = Clade C). Maximum likelihood tree (right) inferred from the combined analysis of molecular data (two mtDNA [CR and Cyt b], two nuclear introns [bSTAT and OSTA5]). Posterior probability values and maximum likelihood bootstrap support (in that order) are shown at the nodes

the Akaike information criterion (AIC) as implemented in jModelTest $[28,29]$. For the concatenated data sets, partitioned analyses were conducted, with data partitioned by gene, with the parameters of nucleotide substitution models unlinked across partitions. Each ML analysis was initiated from a random starting tree, with nodal support assessed using 1000 bootstrap replicates. Two independent Bayes runs of 5 million generations each were performed; each run consisted of four Monte Carlo Markov chains (MCMC), with topologies sampled every 250 generations. The program Tracer 1.6 [30] was used to determine that the effective sample size (ESS) had reached $>200$ for all parameters. A $50 \%$ majority rule consensus tree was constructed using the CONSENSE program in the PHYLIP package [31]. In each simulation the first $20 \%$ of generations were discarded as burn-in, after a pilot run to determine that this was sufficient to achieve stationarity.

\section{Molecular dating}

No Rhinolophidae or Hipposideridae fossils are known from before the middle Eocene, but fossils referable to both families are reported from the middle to late Eocene of Europe [32, 33], including $H$. schlosseri from the late Eocene of France [34]. As fossil calibration points are not available for $H$. commersoni s.l., we expanded the taxonomic sampling used in the molecular clock analysis to allow the use of fossil calibration points. Cyt $b$ sequences were downloaded from GenBank for six species of Hipposideros: H. armiger (DQ865345), H. pratti (EF544427), H. aff. ruber (EU934485), H. aff. caffer (EU934461), H. gigas (EU934469) and $H$. cyclops (EU934466), as well as eight species and 12 individuals of the family Rhinolophidae considered as sister to the Hipposideridae [35, 36]: R. mossambicus (JQ929291, JQ929299), R. eloquens (JQ929284, JQ929285), R. hildebrandtii (JQ929297, JQ929298), $R$. darlingi (EU436675), R. fumigatus (FJ457614), R. landeri (EU436668, FJ457612), R. ruwenzorii (EU436679) and R. maclaudi (FJ185203). As calibration point, we used a minimum of 37 Mya and maximum of 55 Mya for the split between the Rhinolophidae and the Hipposideridae $[20,37,38]$.

Divergence dates between clades were estimated from the expanded $C y t b$ data set using an uncorrelated relaxed lognormal Bayesian molecular clock approach [39], as implemented in BEAST 2.1.3.0 [40]. The HKY + I substitution model was used, with the Yule speciation model as tree prior. As an alternative to fossil calibrated estimate of divergence times, an additional molecular clock analysis was conducted using a fixed mean substitution rate of $1.30 \times 10^{-8} \mathrm{subs} / \mathrm{site} /$ year $[5,41]$. This analysis was performed using the strict molecular clock model in BEAST. All other parameters were the same as in previous analysis. The MCMC chains were run for 30 million generations, with topologies and parameters logged every 1500 generations. Results were evaluated using Tracer v1.6 [30]. The Effective Sample Size (ESS) values were $>200$ for all parameters, suggesting the MCMC chains had sufficiently converged [40]. After discarding the first $25 \%$ of generations 
as burn-in, the maximum clade credibility tree was constructed using TreeAnnotator 1.7.4 (available in the BEAST package), and then visualized with FigTree 1.3.1 [42].

\section{Morphological measurements}

The following standard external measurements were taken from specimens collected in the field before their preparation using a millimeter ruler accurate to the nearest $0.5 \mathrm{~mm}$ : total length (TL), tail length (TAIL), hind foot length (HF) (not including claw), ear length (EAR) and forearm length (FA). Further, body mass (WT) was recorded in grams using a spring balance accurate to the nearest $0.5 \mathrm{~g}$.

Cranial and dental measurements were obtained from cleaned skulls of voucher specimens using digital callipers accurate to the nearest $0.1 \mathrm{~mm}$ and following for the most part Freeman [43]: cranial - greatest skull length (SL), condyle-basal length (CBL), greatest zygomatic breadth (ZYGO), minimum interorbital width (IOW), greatest mastoid breadth (MAST), rostrum length (ROST), palatal length (PAL); and dental - total tooth row (C1-M3), upper molar row (UP MOL R), width at upper canines (C1-C1), width at upper posterior molars (M3-M3), height upper canine (UP CANIN), dentary length (DENT LEN), moment arm of temporal (MOM1 COR), total lower tooth row (I1-M3) and lower tooth row (LOWER TR). Only adult specimens were used in this study, as defined by the eruption of all permanent teeth (often showing some wear), the complete ossification of the basiosphenoid suture, and the development of the sagittal crest. All external and craniodental measurements used in the analyses were made by a single individual (SMG). The number of adult male $H$. commersoni available in the morphometric dataset was limited, and given there is evidence of sexual dimorphism in this species [16, 44], males were excluded from the morphometrics analyses. Intact skulls from 20 adult females were included in this study from 13 localities spanning the latitudinal distribution of $H$. commersoni in western Madagascar.

\section{Statistical analyses}

Shapiro-Wilk's test and Levene's test were implemented to assess the assumptions of normality and equality of variances of variable characters in the dataset. Analysis of Variance (ANOVA) was carried out using post-hoc Tukey tests, to assess morphological and craniodental differences between the derived genetic clades.

Principal component analysis (PCA) was conducted separately on external and craniodental measurements to examine possible segregation of the different molecular clades, as well as geographic variation in H. commersoni. Further hierarchical cluster analysis was implemented using Ward's method on both measurement data sets to provide additional confirmation of the factor loadings obtained and to identify natural groupings among samples
Table 2 Reformed agglomeration table from hierarchical cluster analysis using Ward's method of log-transformed external measurements of Hipposideros commersoni

\begin{tabular}{lccc}
\hline No. of clusters & Agglomeration last step & Coefficients this step & Change \\
\hline 2 & 36.000 & 21.500 & 14.500 \\
3 & 21.500 & 11.308 & 10.192 \\
4 & 11.308 & 6.921 & 4.387 \\
5 & 6.921 & 5.562 & 1.359 \\
6 & 5.562 & 4.286 & 1.276 \\
\hline
\end{tabular}

(Tables 2 and 3) [45, 46]. Data were log-transformed to improve normality and homoscadisticity. All statistical analyses were carried out using SPSS (version 21.0, IBM SPSS Statistics).

\section{Results}

\section{DNA sequencing}

The four genetic markers were successfully amplified for all 31 taxa included in the molecular portion of the study (Table 1). The aligned sequence data for each marker included (Table 1): CR, 481 bp (114 variable sites); Cyt $b$, 705 bp (60 variable sites); STAT, 476 bp (six variable sites); and OSTA5, 676 bp (nine variable sites). The nucleotide composition and the levels of variation of the two marker systems (mtDNA vs nucDNA) differed (Table 4). The mtDNA partition contained the highest number of variable characters (174 variable sites), while the ncDNA data was more conserved (15 variable sites). For the STAT gene, only eight unique haplotypes were identified. The haplotypic diversity for this dataset is high $(\mathrm{h}=0.80)$, but the nucleotide diversity is low $(\pi=0.00274)$. For OSTA5 gene, 10 unique haplotypes were identified. Once again low levels of nucleotide variability were observed $(\pi=0.00264)$. As expected, CR contained the highest proportion of variable characters ( $24 \%$ variable characters) followed by $C y t b$ (9\% variable characters).

\section{Phylogenetic analysis}

The phylogenetic analysis of each nuclear marker independently resulted in largely unresolved trees, which is not surprising given the few number of variable characters observed (Additional file 1: Figure S1 and S2; Table 4). The

Table 3 Reformed agglomeration table from hierarchical cluster analysis using Ward's method of log-transformed craniodental measurements of Hipposideros commersoni

\begin{tabular}{lccc}
\hline No. of clusters & Agglomeration last step & Coefficients this step & Change \\
\hline 2 & 0.252 & 0.143 & 0.109 \\
3 & 0.143 & 0.102 & 0.041 \\
4 & 0.102 & 0.072 & 0.030 \\
5 & 0.072 & 0.059 & 0.013 \\
6 & 0.059 & 0.046 & 0.013 \\
\hline
\end{tabular}


Table 4 Characteristics of datasets used in this study

\begin{tabular}{|c|c|c|c|c|c|c|c|c|}
\hline \multirow[t]{2}{*}{ Gene } & \multirow{2}{*}{$\begin{array}{l}\text { Total number } \\
\text { of individuals }\end{array}$} & \multirow[t]{2}{*}{ Total sites } & \multirow[t]{2}{*}{ Variable sites } & \multirow{2}{*}{$\begin{array}{l}\text { Parsimony informative } \\
\text { sites }\end{array}$} & \multicolumn{4}{|c|}{ Nucleotide frequencies } \\
\hline & & & & & $\% \mathrm{~A}$ & $\% \mathrm{~T}$ & $\% C$ & $\% \mathrm{G}$ \\
\hline$C R$ & 31 & 481 & 114 & 72 & 32.73 & 27.24 & 25.74 & 14.29 \\
\hline Cyt b & 31 & 705 & 60 & 38 & 26.90 & 27.06 & 30.86 & 15.17 \\
\hline bSTAT & 31 & 476 & 6 & 2 & 20.17 & 27.91 & 28.77 & 23.14 \\
\hline OSTA5 & 31 & 676 & 9 & 6 & 23.85 & 25.46 & 27.04 & 23.65 \\
\hline Supermatrix & 31 & 2336 & 189 & 118 & 25.87 & 26.84 & 28.26 & 19.03 \\
\hline
\end{tabular}

Patterns of sequence variability are presented for two mtDNA regions (CR and Cyt $b$ ), two nuclear introns (bSTAT and OSTA5) and the combined data matrix. The total number of nucleotide sites, variable and parsimony informative sites, as well nucleotide frequencies are given for each partition and the combined data matrix

mtDNA marker topologies were better resolved (Additional file 1: Figure S3 and S4). There was no significant (ML bootstrap $>70 \%$; Bayesian posterior probability $>95 \%$ ) conflict among the topologies recovered by the independent analysis of the four molecular markers [47] and the molecular data was concatenated (2336 bp, 118 variable characters). The ML and Bayesian analysis of the concatenated data matrix (mtDNA + ncDNA; Fig. 1) did not recover $H$. commersoni as a single monophyletic lineage. Two $H$. commersoni specimens (collected from the Isalo National Park, FMNH 175970, and from Itampolo, FMNH 184173) were placed in close association (ML bootstrap, 64; Bayes' posterior probability, 1.00) to African $H$. gigas and $H$. vittatus (Clade A; Fig. 1). Clade A is genetically distant from the other Malagasy $H$. commersoni specimens. This level of divergence $(2.6 \%$ between Clades A and $\mathrm{C}$ to $3.1 \%$ between Clades A and B [Table 5]) based on $C y t b$ uncorrected mean pairwise divergence is notable given that other $H$. commersoni specimens collected from these two localities cluster within Clade B (ML bootstrap, 99; Bayesian posterior probability, 1.00) together with specimens from localities in the southwest (Fig. 1). Clade C consists exclusively of specimens collected from the north. Clades B and C form a well-supported monophyletic lineage (ML bootstrap, 97; Bayes' posterior probability, 1.00), sister to the lineage which includes Clade A, $H$. gigas and H. vittatus (ML bootstrap, 64; Bayes' posterior probability, 1.00). These data strongly suggest the presence of several independently evolving lineages within $H$.

Table 5 Uncorrected mean pairwise distances based on analyses of the CR (below the diagonal) and Cyt b gene (above the diagonal) between major lineages of Hipposideros commersoni (Clades A, B, C) identified in the molecular analyses, H. gigas and H. vittatus

\begin{tabular}{llllll}
\hline & Clade A & Clade B & Clade C & H. gigas & H. vittatus \\
\hline Clade A & & 0.031 & 0.026 & 0.032 & 0.029 \\
Clade B & 0.072 & & 0.019 & 0.031 & 0.028 \\
Clade C & 0.101 & 0.058 & & 0.025 & 0.026 \\
H. gigas & 0.072 & 0.083 & 0.096 & & 0.029 \\
H. vittatus & 0.074 & 0.077 & 0.090 & 0.069 & \\
\hline
\end{tabular}

commersoni. Clades B and C are geographically structured, with Clade $\mathrm{C}$ including specimens collected from northern Madagascar, while members of Clade B are more widely distributed in the south.

Uncorrected pairwise sequence distances for the two mtDNA regions (CR and $C y t b)$ are presented in Table 5. Genetically, Clade A is as distant from the $H$. gigas- $H$. vittatus species pair (respectively $3.2 \%$ and $2.9 \%$ ) as it is from other H. commersoni placed in Clades B and C, again highlighting the uniqueness of this lineage.

\section{Molecular clock dating}

The maximum clade probability tree (Fig. 2) inferred in BEAST supports the Garli and MrBayes phylogenies. Our analyses recovered $H$. commersoni Clade A as basal to all other members of the $H$. commersoni species group $(H$. commersoni Clades B \& C, H. gigas and $H$. vittatus). This suggests that $H$. commersoni Clades $\mathrm{B}$ and $\mathrm{C}$ are more closely related to the African taxa $H$. gigas and $H$. vittatus than to other Malagasy $H$. commersoni (Clade A). Molecular clock estimates using fossil calibration suggest that Clade A diverged from its sister taxa ( $H$. vittatus, $H$. gigas, $H$. commersoni Clade B and C) during the Miocene (5.81 MYA; 95 \% HPD 2.24-13.93). This divergence event is older than the separation of other established species groups, for example Rhinolophus mossambicus and R. fumigatus, which our molecular clock estimates suggests diverged 4.80 MYA (95\% HPD 1.90-9.45), and R. ruwenzorii and $R$. maclaudi, which diverged 3.86 MYA (95 \% HPD 1.11-8.54) [37]. Clades $\mathrm{B}$ and $\mathrm{C}$ of the $H$. commersoni group last shared a common ancestor during the Pliocene (3.38 MYA; 95 \% HPD 1.32-8.48, Fig. 2). The estimated divergence times using the substitution rate calibrated molecular clock resulted in more recent divergence dates (Additional file 2: Figure S5). For example, molecular clock estimates suggest that Clade A diverged from its sister taxa 4.20 MYA (95 \% HPD 1.99-13.73) and the two sister Clades B \& C shared their last common ancestor 2.55 MYA (95 \% HPD 1.15-7.89, Table 6). The $95 \%$ HPD intervals for divergence events from both analyses (fossil calibrated and substitution rate calibrated) were broad and but did not show considerable overlap. From Taylor et al. [37], 


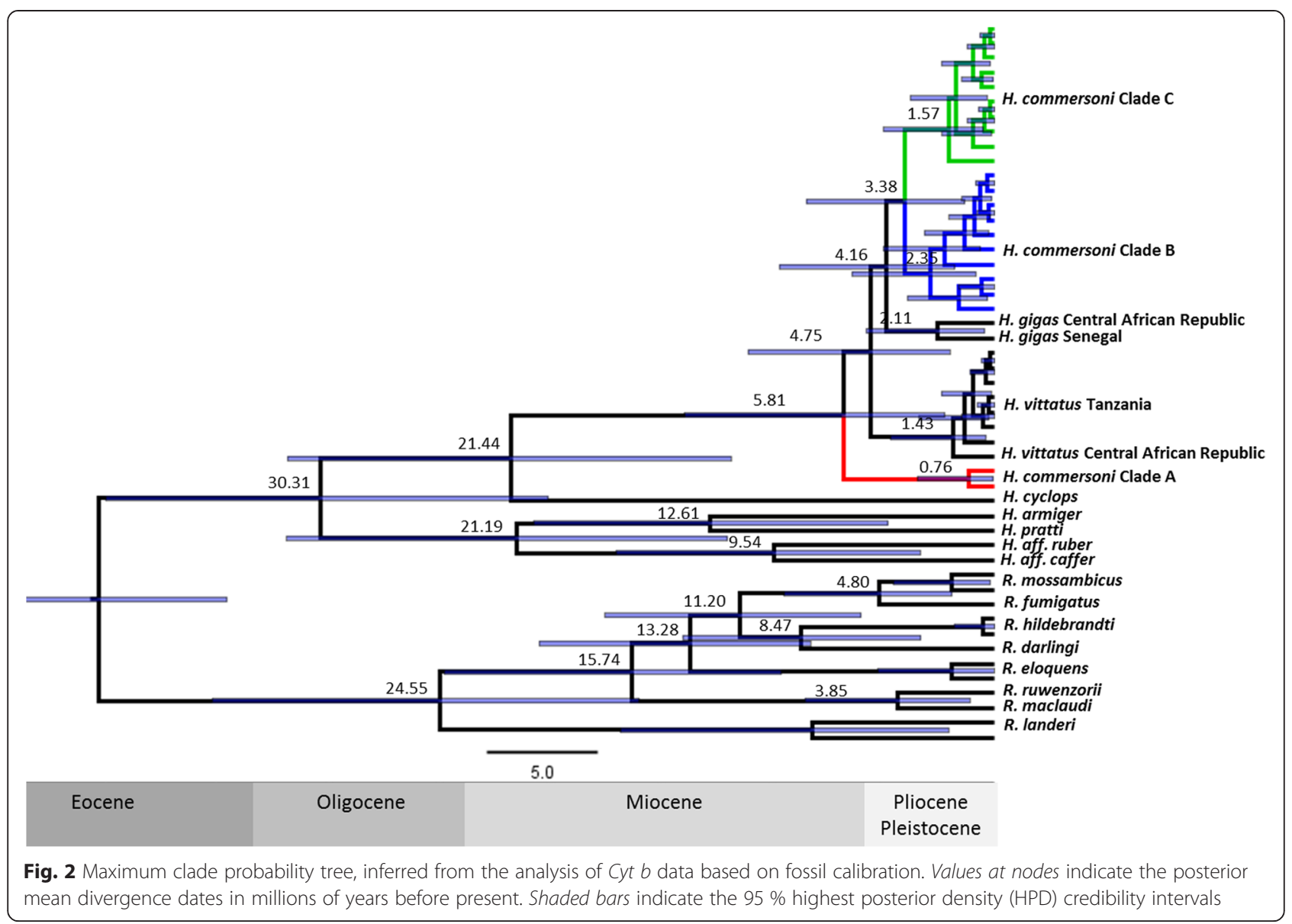

$R$. mossambicus and $R$. fumigatus, diverged 6.96 MYA, which is older than our estimate and $R$. ruwenzorii and $R$. maclaudi about 2.99 MYA, which is more recent than our estimated. We suggest that using a calibration point allowed BEAST to estimate a more realistic clock rate. The substitution rate of 1.0 in the fossil calibrated clock allowed the determination of relative rates for each recovered clade.

Table 6 Divergence dates between major lineages of Hipposideros commersoni (Clades A, B, C) and $H$. gigas and $H$. vittatus

\begin{tabular}{llllll}
\hline & \multicolumn{2}{l}{$\begin{array}{l}\text { Divergence times using } \\
\text { fossil calibration point }\end{array}$} & & \multicolumn{2}{l}{$\begin{array}{l}\text { Divergence times using } \\
\text { fixed mean substitution rate }\end{array}$} \\
\cline { 2 - 3 } Node: & Mean & $95 \%$ HPD (Mya) & & Mean & $95 \%$ HPD (Mya) \\
\hline Clade A & 5.80 & $2.24-13.93$ & & 4.20 & $1.97-13.73$ \\
H. vittatus & 4.75 & $2.01-11.09$ & & 3.68 & $1.80-10.88$ \\
H. gigas & 4.16 & $1.77-9.68$ & & 3.17 & $1.50-9.00$ \\
Clade B \& C. & 3.38 & $1.32-8.48$ & & 2.55 & $1.15-7.99$ \\
\hline
\end{tabular}

Two molecular clock analyses were conducted. Fossil-calibrated values were estimated using a Bayesian lognormal relaxed-clock model, while the substitution rate calibrated values were estimated using the strict molecular clock model using a fixed mean substitution rate of $1.30 \times 10^{-8}$ subs/site/year. The mean estimated values and the $95 \%$ highest posterior density (HPD) ranges are given for the two molecular clocks. See Fig. 2 for the corresponding maximum clade probability trees

\section{Morphometrics}

As Clade A was only comprised of two individuals, statistical comparisons were only made between animals belonging to Clades B and C. Shapiro-Wilk's test $(P>0.05)$ and a visual inspection of their histograms showed that the variable characters in the dataset were normally distributed. Levene's test verified the equality of variances in the samples $(P>0.05)$.

Analysis of variance (ANOVA) revealed significant variation in four of six external variables and 15 of 16 craniodental variables when taxa were sorted into Clades A, B or $\mathrm{C}$ following the results of molecular analyses (Table 7 ). Clade A is morphologically similar to Clade B, but is morphologically differentiated from Clade $C$ (Table 7). The larger Clade $C$ bats had significantly greater total length, tail length, ear length and forearm length than specimens assigned to Clade B, yet there were no significant differences in hindfoot length and body mass between the clades (Table 7). In parallel, craniodental measurements were significantly larger in Clade $C$ than Clade B, except minimum interorbital width (Table 7).

The first two unrotated principal components (PC1 and PC2) explained $67.6 \%$ of the total variance in external measurements (Fig. 3a) and $88.2 \%$ of total variance in cranialdental morphology (Fig. 3b). PCA plots of external and 
Table 7 Summary of body mass, external body and craniodental measurements, and results of one-way ANOVAs and Tukey post hoc tests for Hipposideros commersoni based on the molecular clades defined in this study

\begin{tabular}{|c|c|c|c|c|}
\hline Variable & & Clade A & Clade C & Clade B \\
\hline \multicolumn{5}{|l|}{$\mathrm{TL}$} \\
\hline & N & 2 & 9 & 8 \\
\hline & Mean & 121.0 & 133.6 & 125.6 \\
\hline & Std. Deviation & - & 4.50 & 7.23 \\
\hline & Minimum & 119 & 125 & 115 \\
\hline & Maximum & 123 & 138 & 137 \\
\hline
\end{tabular}

TAIL

7.03

\begin{tabular}{ll}
\multicolumn{2}{l}{ One-way ANOVA } \\
\hline$F_{(2,16)}$ & $P$ \\
\hline 6.50 & 0.01
\end{tabular}

8

N

Mean

Std. Deviation

Minimum

Maximum

HF

N

Mean

Std. Deviation

Minimum

Maximum

EAR

N

Mean

Std. Deviation

Minimum

Maximum

FA

N

Mean

Std. Deviation

Minimum

Maximum

WT

N

Mean

Std. Deviation

Minimum

Maximum
2

32

-

30

34

2

14.5

0.71

14

15

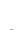

26.5

-

26

27

2

80.5

-

80

81

2

40.5

-

26

55

$\begin{array}{cc}9 & 8 \\ 36.8 & 31.0 \\ 2.91 & 3.66 \\ 31 & 25 \\ 41 & 35\end{array}$

125.6

137 Post hoc Tukey tests $P=0.03 ;$

Clade $\mathrm{B}<\mathrm{C}$ 
Table 7 Summary of body mass, external body and craniodental measurements, and results of one-way ANOVAs and Tukey post hoc tests for Hipposideros commersoni based on the molecular clades defined in this study (Continued)

\begin{tabular}{lccc}
\hline $\mathrm{SL}$ & & & \\
$\mathrm{N}$ & 2 & 8 & 7 \\
Mean & 26.95 & 29.72 & 28.08 \\
Std. Deviation & - & 0.67 & 1.20 \\
Minimum & 26.5 & 28.2 & 26.6 \\
Maximum & 27.4 & 30.5 & 29.9
\end{tabular}

CBL

$\mathrm{N}$

Mean

Std. Deviation

Minimum

Maximum

N

Mean

Std. Deviation

Minimum

Maximum

IOW

$\mathrm{N}$
Mean
Std. Deviation
Minimum
Maximum

MAST

Mean

Std. Deviation

Minimum

Maximum

ROST

N
Mean
Std. Deviation
Minimum
Maximum

PAL
N

Mean

\section{2}

23.9

-

23.6

24.2

2

14.1

-

13.6

14.6

2

2.9

$-$

2.6

3.2

2

12.2

11.7

12.7
8

26.34

0.60

25.1

27.1

6.32

8

15.65

0.59

15

16.8

8

3.01

0.13

2.8

3.2

5.91

8

13.67

0.51

12.9

14.4

4.34

8

11.70

0.38

11

12.1

11.2

2

3.65

7

24.78

1.12

23.4

26.6

0.01

7

14.83

0.64

14.1

15.8

0.36

7

2.93

0.26

2.6

3.3

0.034

7

12.91

0.69

12.2

13.9

7

10.94

0.68

10.1

12
$9.82 \quad 0.002$

8.08

1.20

29.9
9.68

$P=0.038$;

Clade $B<C$

$P=0.011 ;$

Clade $B<C$

$P=0.009$

Clade $\mathrm{B}<\mathrm{C}$

$P=0.014 ;$

Clade $\mathrm{B}<\mathrm{C}$ 
Table 7 Summary of body mass, external body and craniodental measurements, and results of one-way ANOVAs and Tukey post hoc tests for Hipposideros commersoni based on the molecular clades defined in this study (Continued)

\begin{tabular}{llll}
\hline Std. Deviation & - & 0.27 & 0.43 \\
Minimum & 3.2 & 4 & 3.7 \\
Maximum & 4.1 & 4.8 & 4.9
\end{tabular}

C1-M3

$\begin{array}{llcl}N & & & \\ \mathrm{~N} & 2 & 8 & 7 \\ \text { Mean } & 9.45 & 10.55 & 9.79 \\ \text { Std. Deviation } & - & 0.26 & 0.50 \\ \text { Minimum } & 9.3 & 10 & 9.3 \\ \text { Maximum } & 9.6 & 10.8 & 10.8\end{array}$

UP MOL R

N

Mean

Std. Deviation

Minimum

Maximum

C1-C1

N
Mean
Std. Deviation
Minimum
Maximum

M3-M3

N

Mean

Std. Deviation

Minimum

Maximum

UP CANIN

N
Mean
Std. Deviation
Minimum
Maximum

DENT LEN

$\begin{array}{lll}2 & 8 & 7 \\ 7.35 & 7.87 & 7.36 \\ - & 0.17 & 0.31 \\ 7.3 & 7.6 & 7 \\ 7.4 & 8.2 & 8\end{array}$

9.79

11.69

\section{8}

8.16

0.46

7.3

8.7

(

10.97 
Table 7 Summary of body mass, external body and craniodental measurements, and results of one-way ANOVAs and Tukey post hoc tests for Hipposideros commersoni based on the molecular clades defined in this study (Continued)

\begin{tabular}{|c|c|c|c|c|c|c|c|}
\hline & Maximum & 17.9 & 20 & 19.6 & & & \\
\hline \multirow[t]{6}{*}{ MOM1 COR } & & & & & 4.01 & 0.042 & ns \\
\hline & $\mathrm{N}$ & 2 & 8 & 7 & & & \\
\hline & Mean & 5.65 & 6.22 & 5.76 & & & \\
\hline & Std. Deviation & - & 0.21 & 0.49 & & & \\
\hline & Minimum & 5.5 & 6.0 & 5.0 & & & \\
\hline & Maximum & 5.8 & 6.6 & 6.4 & & & \\
\hline \multirow[t]{7}{*}{$11-\mathrm{M} 3$} & & & & & 7.78 & 0.005 & $P=0.014$ \\
\hline & & & & & & & Clade $\mathrm{B}<\mathrm{C}$ \\
\hline & $\mathrm{N}$ & 2 & 8 & 7 & & & \\
\hline & Mean & 11.75 & 12.99 & 12.13 & & & \\
\hline & Std. Deviation & - & 0.30 & 0.70 & & & \\
\hline & Minimum & 11.6 & 12.5 & 11.1 & & & \\
\hline & Maximum & 11.9 & 13.3 & 13.2 & & & \\
\hline \multirow[t]{7}{*}{ LOWER TR } & & & & & 11.20 & 0.001 & $P=0.003$ \\
\hline & & & & & & & Clade $\mathrm{B}<\mathrm{C}$ \\
\hline & $N$ & 2 & 8 & 7 & & & \\
\hline & Mean & 10.70 & 11.87 & 10.97 & & & \\
\hline & Std. Deviation & - & 0.27 & 0.57 & & & \\
\hline & Minimum & 10.5 & 11.5 & 10.2 & & & \\
\hline & Maximum & 10.9 & 12.2 & 11.9 & & & \\
\hline
\end{tabular}

See materials and methods for definitions of variable acronyms. ns = not significant

craniodental variables recovered Clades B and C as two distinct groups with little overlap. In contrast, individuals of Clades A and B overlapped in morphological variables. Because several of the external morphology variables and most of the craniodental variables loaded high on PC1, we interpreted this component as a proxy for size. Both sets of variables suggest that $H$. commersoni Clades $\mathrm{A}$ and $\mathrm{B}$ are smaller than those from Clade $C$ (Fig. 3). In the case of external measurements, PC2 showed an inverse relationship between tail length and hind foot length - bats that had high loadings on PC2 had a relatively long tail but short hind foot, whereas bats that had low loadings on PC2 had a relatively short tail but long hind foot (Table 8 ). In the case of craniodental variables, $\mathrm{PC} 2$ indicated skull robustness (Table 9) - bats that loaded high on PC2 had a relatively larger interorbital width than bats that loaded low on PC2.

Two major clusters were recovered from the dendrograms produced by the hierarchical cluster analyses of external and craniodental variables, supporting the PCA analysis. The first cluster, recovered in both dendrograms, included all eight individuals from northern Madagascar assigned to Clade $\mathrm{C}$ and two animals genetically assigned to Clade B (FMNH 221308 from Ankarana and FMNH 175777 from Namoroka). The second cluster contained the smaller southern individuals from Clades A and B (Fig. 4), which confirms that the two genetically divergent animals belonging to Clade $\mathrm{A}$ are morphologically similar to animals from Clade B.

\section{Discussion}

This study combines evidence from molecular (mtDNA and ncDNA) and morphological characters to provide support for the reciprocal monophyly of several independently evolving lineages within Hipposideros commersoni, occurring on Africa and nearby islands, as well on Madagascar. One of the principal questions addressed is the evolutionary history and systematic relationships of Malagasy populations currently assigned to $H$. commersoni, as well as African populations currently placed within the $H$. commersoni species group [1].

The results suggest that previous taxonomic treatments of the group underestimated species diversity of $H$. commersoni and that a cryptic species appears to be present. Although our geographic sampling did not cover the complete range of this species, specifically the eastern portion of the island, the results indicate nonmonophyly with respect to Madagascar of different recovered Malagasy clades.

Single locus or multilocus molecular data and/or morphological differences have been used previously to identify 


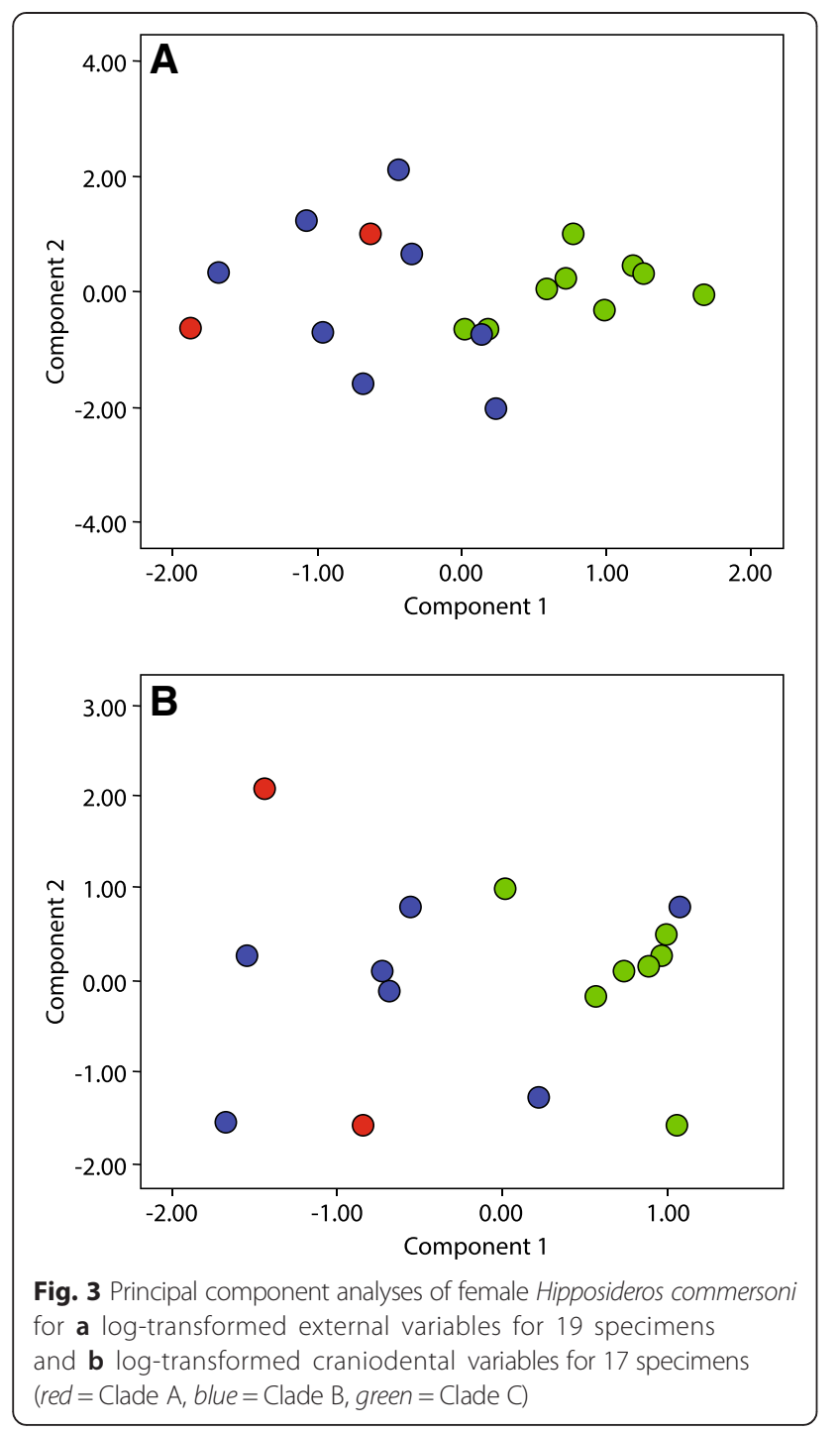

cryptic species diversity in southeast Asian $[10,48,49]$ and African [50,51] hipposiderids. Based on an analysis of the $H$. larvatus species complex using mitochondrial control region markers, morphology and bioacoustics two forms were identified (H. khasiana and $H$. grandis) that were differentiated based on haplotypic structure and phonics [52].

Table 8 Character loading for the first three components $(P C)$ in a Principal Component analysis based on external measurements of Hipposideros commersoni

\begin{tabular}{lllr}
\hline Variable & PC1 & PC2 & \multicolumn{1}{c}{ PC3 } \\
\hline TAIL & 0.543 & 0.566 & 0.518 \\
HF & 0.541 & -0.657 & 0.263 \\
EAR & 0.850 & -0.197 & -0.185 \\
FA & 0.824 & -0.317 & -0.172 \\
TL & 0.774 & 0.308 & 0.265 \\
WT & 0.519 & 0.461 & -0.636 \\
\hline
\end{tabular}

Table 9 Character loading for the first three components (PC) in a principal component analysis based on craniodental measurements of Hipposideros commersoni

\begin{tabular}{llll}
\hline Variable & PC1 & PC2 & PC3 \\
\hline SL & 0.980 & -0.140 & -0.026 \\
CBL & 0.980 & -0.110 & -0.034 \\
ZYGO & 0.898 & -0.288 & 0.171 \\
IOW & 0.396 & 0.805 & 0.315 \\
MAST & 0.909 & -0.264 & 0.048 \\
ROST & 0.800 & 0.051 & 0.446 \\
PAL & 0.865 & -0.315 & 0.019 \\
C1-M3 & 0.972 & 0.039 & -0.071 \\
UP MOL R & 0.869 & 0.258 & 0.021 \\
C1-C1 & 0.925 & -0.222 & -0.129 \\
M3-M3 & 0.976 & 0.034 & 0.010 \\
UP CANIN & 0.688 & 0.578 & -0.342 \\
DENT LEN & 0.977 & -0.038 & -0.082 \\
MOM1 COR & 0.908 & -0.035 & 0.200 \\
I1-M3 & 0.951 & 0.137 & -0.210 \\
LOWER TR & 0.960 & 0.114 & -0.149 \\
\hline
\end{tabular}

In another example, $H$. khaokhouaensis from Laos is similar in general body size and shape to its sister species $H$. rotalis, but differs in aspects of the noseleaf, skull structure related to bioacoustics and echolocation frequency [4]. The phylogenetic relationships within the African $H$. ruber species complex were investigated [51] using $C y t b$ to determine the taxonomic status of two divergent genetic forms often found in sympatry in Senegal, which might represent cryptic species despite being morphologically indistinguishable. However, in this latter case, absence of nuclear gene flow between these two reputed forms remains to be investigated to demonstrate their reproductive isolation.

All $H$. commersoni sequenced in the current study were from the western half or extreme north of Madagascar. The molecular analyses presented herein indicate that $\mathrm{H}$. commersoni as currently diagnosed is not monophyletic with respect to Madagascar, and with strong support for the presence of divergent lineages. As two individuals from Isalo (FMNH 175970) and Itampolo (FMNH 184173) form a well-supported monophyletic group (Clade A), basal to African $H$. vittatus and H. gigas, and separate from the balance of Malagasy $H$. commersoni (Clades B and C), a single origin of this species complex on the island is not supported. The long branches separating these clades (ranging from 2.6 to $3.2 \%$ uncorrected sequence divergence) indicate relatively deep independent evolutionary trajectories of several million years based on molecular clock inferences. Although Clade A was only significantly supported by the mitochondrial data, this is not surprising, given the relatively conservative nature of the nuclear markers 


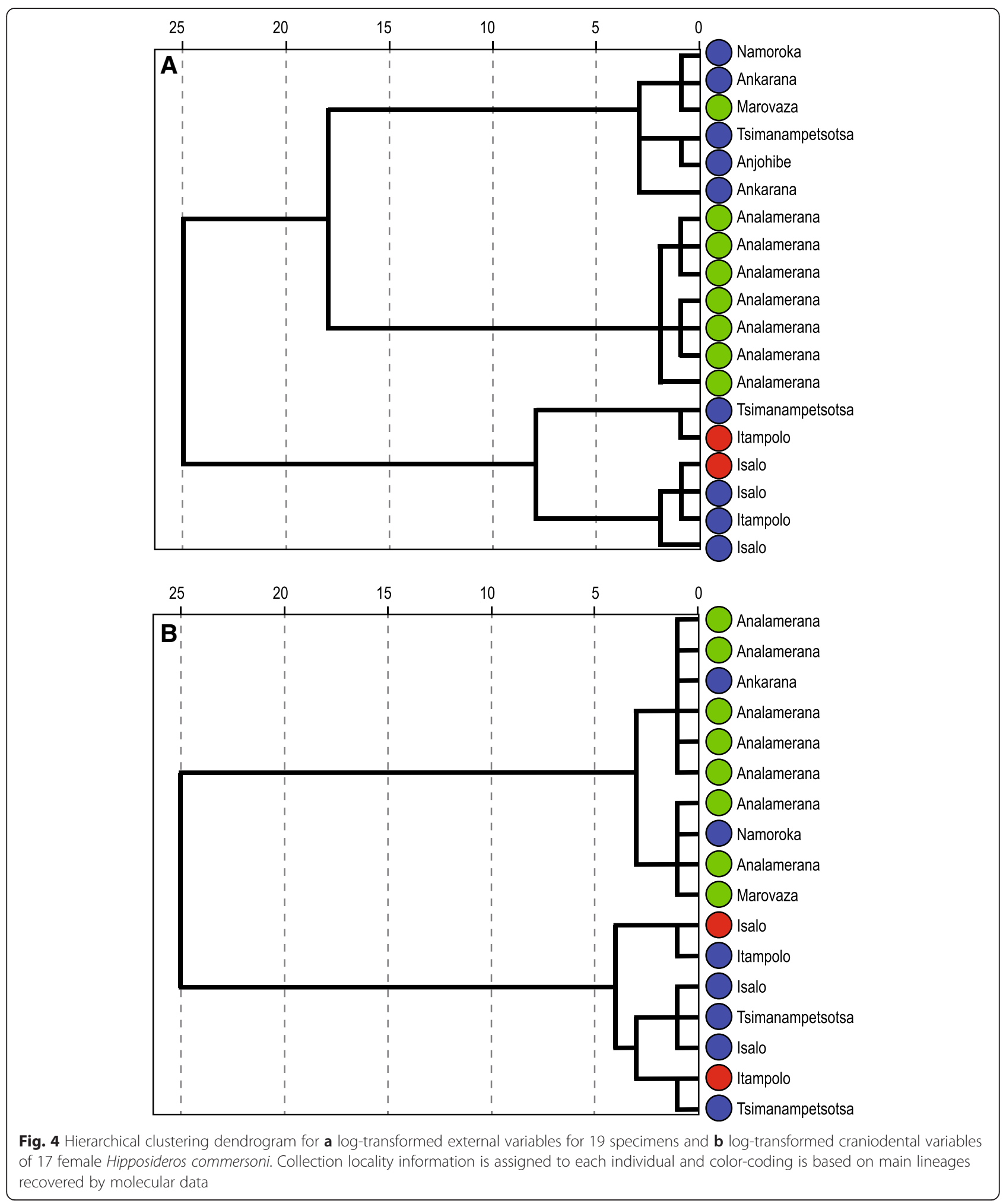

sequenced. The absence of haplotype sharing in OSTA5 gene for Clades B and C, however, does indicate at least some degree of genetic isolation between these two groups. These results indicate that members of the H. commersoni species group do not represent a single widespread AfroMalagasy taxon. Furthermore, the molecular data supports a certain level of divergence between Clades B (in the north) and $C$ (in the south). Additional samples are needed 
to ascertain whether the recovered phylogeny is an artefact of sampling or the result of isolation by distance. The sequence divergence of Clade $\mathrm{A}$ with respect to the balance of H. commersoni (Clades B and C) is comparable with that observed between African $H$. vittatus and $H$. gigas, and based on the molecular clock analysis, it is estimated that the Clade A lineage diverged from its sister taxa during the Miocene.

Genetic divergence in mitochondrial genes varies widely among species. Avise [53] highlighted that due to the matrilineal nature of inheritance of mitochondrial genes, relatively deep divergences do not necessarily correspond to species boundaries. Further, significant nuclear gene flow may occur among divergent mitochondrial phylogroups. Using the published literature, Baker and Bradley [54] found an interval of 3.3-14.7 \% uncorrected genetic distance between sister species of bats, and distances ranging from $0.6-2.3 \%$ encompassing intraspecific variation. These values have been corroborated by recent studies of cryptic species of Asian Hipposideros, which show three different levels of interspecific divergences: 1 ) as low as $3.9 \%$, with supporting evidence from external and craniodental morphology, as well as bioacoustics [4];2) an intermediate level of $6.5 \%$, with corroborating evidence from bioacoustics [55]; and 3) as high as $13.4 \%$, with corroborating evidence from bioacoustics [52]. The sequence divergence values recovered in the current study separating Clade A from other H. commersoni (Clades B and C) suggest that previous taxonomic conclusions underestimated the species diversity of Malagasy bats currently classified as $H$. commersoni.

Within the portion of the phylogeny composed of most individuals assigned to $H$. commersoni, the molecular data support two largely geographically non-overlapping clades: a northern group (Clade $\mathrm{C}$ ) with a relatively limited range and a southern group with a broader geographical distribution (Clade B). The molecular clock analyses indicate that these two clades diverged from one another approximately 3.38 MYA. Morphometric analyses are generally consistent with the molecular data, suggesting a north-south break between animals assigned to Clades B and C. The exception was in Ankarana (far north), where the two lineages cooccur but individuals from each clade could not be differentiated based on multivariate analyses of external and craniodental measurements (Fig. 4). Patterns of morphological variation were not uniform or falling along well-defined clines, such as latitude, and members of these two clades do not completely separate from one another. In term of genetics, based on currently available samples, Clades B and Clade $\mathrm{C}$ are differentiated, for example, the uncorrected $C y t b$ sequence divergence is $1.9 \%$. In the case of the two individuals falling within Clade A, they are genetically distinct from those in Clade B, but show no apparent morphological differentiation. Hence, we interpret this variation as some form of incipient speciation between animals assigned to Clades B and C.

Ramasindrazana et al. [44] have recently analyzed echolocation calls of animals referred to as $H$. commersoni captured in western Madagascar. They found latitudinal variation - animals from the north being larger and emitting lower call frequencies and those from the south smaller and emitting higher call frequencies. On average, females, referred to $H$. commersoni, from the north (Ankarana) deviate from the allometric relationship with lower resting frequency of echolocation calls than predicted from body size. These authors suggested that this pattern might be explained by either regional variation in bioacoustics, intra-island migratory movements or the presence of a cryptic species. The animals that deviated from the pattern were not sequenced in this current study and no further interpretation can be offered.

\section{Evolution of Malagasy Hipposideros}

A particularly striking result of the current analyses is the existence of a previously unrecognized clade of Malagasy $H$. commersoni (Clade A), estimated to have diverged from sister taxa (Malagasy H. commersoni Clades B and C, and African $H$. gigas and $H$. vittatus) during the late Miocene (5.81 MYA). Hipposideros gigas and H. vittatus are more closely related to $H$. commersoni Clades B and C, suggestive of two dispersal hypotheses. The first scenario is that Clade A and Clade B-C originated from two independent African mainland-to-Madagascar dispersal events, with Clade A arriving on the island during the Miocene (approximately 5.8 MYA) and Clade B-C more recently (approximately $3.38 \mathrm{MYA}$ ). A second hypothesis is that the H. commersoni group evolved on Madagascar and at some point after the end of the Miocene, a population related to Clade A crossed the Mozambique Channel and colonized the African continent leading to two recognized extant forms, $H$. vittatus and $H$. gigas, that are morphologically and karyologically similar $[17,36]$. Following this second hypothesis, speciation took place within the Malagasy population, giving rise to Clades $\mathrm{B}$ and $\mathrm{C}$ representing the most recent branch of this lineage.

Madagascar was cooler and drier during periods of Pleistocene glaciation, which lead to habitat shifts and forced some taxa to retreat into refugia [56-58], in different high mountain areas [59]. Expansion from refugia would have occurred during warmer periods. Hipposideros bones from relatively recent geological deposits are known from several sites on the island [60]. Subfossils from Tsimanampetsotsa, extreme southwest, identified as Hipposideros were slightly smaller than typical H. commersoni [61], which occur in this region today [11]. Samonds [62] conducted research on Hipposideros subfossils from Anjohibe Cave in the northwest of Madagascar, and the excavated fossils were dated between 10,000 and 80,000 years ago. Samonds [62] 
identified three morphological forms of Hipposideros from these deposits: 1) those fitting with extant $H$. commersoni; 2), $H$. besaoka, which was described as a new species, being larger and more robust than H. commersoni; and 3), Hipposideros sp. cf. H. commersoni, which appeared to have some dental differences from modern $H$. commersoni. Hipposideros besaoka and $H$. commersoni were sympatric and presumably living in the Anjohibe Cave during the same period, and they show a small amount of overlap in some dental measurements, not related to sexual dimorphism [62]. Our morphological and molecular data suggests parallel results in modern populations of $H$. commersoni, with Clade $\mathrm{B}$ and $\mathrm{C}$ known to occur in sympatry at one northern locality. This raises the intriguing possibility that one of the phylogenetic clades identified in this paper (Clade B or Clade C), might be referable to $H$. besaoka and, in this case, this species is not extinct. Further fine-scale phylogeographic studies using variable nuclear markers such as microsatellites are needed to clarify species boundaries and give a greater understanding of the processes underpinning the evolution of these taxa across Madagascar.

\section{Geographically correlated population structure}

Within $H$. commersoni (Clade B-C), the molecular data support two regionally associated clades: a small-bodied southern group with a broad geographical distribution (Clade B) and a large-bodied northern group (Clade C) with a relatively limited range. The molecular clock analyses indicate that these two clades diverged from one another approximately 3.38 MYA. Morphometric data are consistent with the molecular data, suggesting a north-south break in distribution. These two lineages are not completely allopatric. In Ankarana, sequenced individuals assigned to these two genetic clades could not be distinguished using external and craniodental measurements (Fig. 3). The morphometric data in the present study is consistent with conclusions of a previous study on geographic variation in morphology of this taxon in western Madagascar [16]. Specimens grouped into two distinct morphotypes, a larger morphotype found in northern Madagascar (from Analamerana to Ankarana and south to Bemaraha) and a smaller morphotype widely distributed in the south, from Isalo to Tsimanampetsotsa. Ranivo and Goodman [16] found that male $H$. commersoni do not show the same pattern and are largely homogenous in size across these zones.

At least three other Malagasy bat species, Paratriaenops furculus [63], Chaerephon leucogaster [64] and Myotis goudoti [65] show similar haplotypic segregation along a latitudinal gradient. However, the latitudinal distribution of different clades and the calculated expansion periods of the other species differ from late Pleistocene in M. goudoti to early Holocene in C. leucogaster, suggesting that no common historical process underlies the different demographic events between these taxa $[64,65]$.
Ranivo and Goodman [16] found both H. commersoni morphotypes in Isalo. The morphologically divergent animals from Isalo included two specimens (FMNH 175973 and 175975) that were collected on the same day and at the same cave site as the Isalo specimen (FMNH 175970) analyzed in our molecular study, which falls into Clade A. This latter specimen morphologically aligns with the smaller southern individuals, while FMNH 175973 and 175975 are of the larger northern morphotype. This may indicate some form of intraisland movements.

In eastern Africa, seasonal fluctuations in abundance of prey utilized by large hipposiderids are pronounced, which can result in food shortages during the cool dry season. These shifts in the resource base have been invoked to explain local seasonal movement in $H$. vittatus/ $H$. gigas to areas with greater food abundance $[7,66]$. It is unclear if $H$. commersoni remains inactive in caves during times of resource shortage or if local populations migrate to other sites. Large hipposiderid bats have high wing loading and low to medium aspect ratios [67], which may favor relatively quick, long-distance movements, allowing certain populations to track food resources $[68,69]$. The colonization and speciation history of $H$. commersoni on Madagascar, as represented by a single species occurring on the island, is certainly more complex than currently understood. Further studies including increased spatial sampling and the use of additional molecular markers particularly faster evolving nuclear markers are needed to fully resolve the evolutionary history and associated systematics of the different clades occurring on Madagascar.

\section{Conclusions}

This study provides evidence, particularly from mitochondrial data, for the existence of at least two sympatricallyoccurring species of the genus Hipposideros on Madagascar. Absence of nuclear gene flow between groups remains to be established to verify their reproductive isolation, yet the lack of haplotype sharing in OSTA5 for Clades B and C indicates some degree of genetic isolation between these clades. Subfossil evidence indicates that in the recent geological past two species, $H$. commersoni and the presumed extinct $H$. besaoka, occurred in sympatry [62]. Given that we have recovered two genetically distinct lineages of $H$. commersoni (Clades B and $\mathrm{C}$ ) living on occasion in sympatry, this might indicate that one of them is $H$. besaoka and, hence, still extant. A detailed morphological comparison of the type series of Samonds' [62] H. besaoka with modern $H$. commersoni represented in our data is needed to test this intriguing possibility and crucial before the description of a possible undescribed species. 


\section{Appendix 1}

Table 10 Collection details of specimens of Hipposideros commersoni included in analyses of external and cranio-dental morphometry and and molecular variation

\begin{tabular}{|c|c|c|c|c|c|c|c|}
\hline Museum number & $\begin{array}{l}\text { Province/Locality (numbers in parentheses } \\
\text { refer to those shown in Fig. 1) }\end{array}$ & $\begin{array}{l}\text { Clade } \\
\text { (from Fig. 2) }\end{array}$ & Latitude & Longitude & Collection date & Sex & Alt. $(\mathrm{m})$ \\
\hline FMNH 169707 & $\begin{array}{l}\text { Antsiranana/RS d'Ankarana, } 2.6 \mathrm{~km} \mathrm{E} \\
\text { Andrafiabe, near Andrafiabe Cave }\end{array}$ & C & 49.0567 & -12.9317 & November 2001 & Female & 50 \\
\hline FMNH 175777 & $\begin{array}{l}\text { Mahajanga/RNI de Namoroka, near source of } \\
\text { Mandevy River, } 32 \text { km NW Andranomavo }\end{array}$ & B & 45.345 & -16.38 & October 2002 & Female & 100 \\
\hline FMNH 175966 & $\begin{array}{l}\text { Fianarantsoa/just outside PN de l'Isalo, along } \\
\text { Menamaty River, } 8 \text { km N Ranohira (RN7) }\end{array}$ & B & 45.3917 & -22.4856 & December 2002 & Female & 700 \\
\hline FMNH 175970 & $\begin{array}{l}\text { Fianarantsoa/PN de I'Isalo, along Sahanafa } \\
\text { River, } 28 \mathrm{~km} \text { SE Berenty-Betsileo }\end{array}$ & A & 45.2933 & -22.3167 & December 2002 & Female & 550 \\
\hline FMNH 176155 & Toliara/Forêt des Mikea, 9.5 km W Ankiloaka & B & 43.5233 & -22.7783 & February 2003 & Male & 80 \\
\hline FMNH 177302 & Mahajanga/SF d'Ampirojoa & B & 46.81 & -16.315 & April 2003 & Male & 100 \\
\hline FMNH 178806 & $\begin{array}{l}\text { Antsiranana/RS d'Analamerana, Grotte de } \\
\text { Bazaribe, } 3.6 \text { km SE Menagisy }\end{array}$ & C & 49.47352 & -12.7121 & January 2004 & Female & 90 \\
\hline FMNH 178808 & $\begin{array}{l}\text { Antsiranana/RS d'Analamerana, Grotte de } \\
\text { Bazaribe, } 3.6 \text { km SE Menagisy }\end{array}$ & C & 49.47352 & -12.7121 & January 2004 & Female & 90 \\
\hline FMNH 178809 & $\begin{array}{l}\text { Antsiranana/RS d'Analamerana, Grotte de } \\
\text { Bazaribe, } 3.6 \text { km SE Menagisy }\end{array}$ & C & 49.47352 & -12.7121 & January 2004 & Female & 90 \\
\hline FMNH 178810 & $\begin{array}{l}\text { Antsiranana/RS d'Analamerana, Grotte de } \\
\text { Bazaribe, } 3.6 \text { km SE Menagisy }\end{array}$ & C & 49.47352 & -12.7121 & January 2004 & Female & 90 \\
\hline FMNH 178811 & $\begin{array}{l}\text { Antsiranana/RS d'Analamerana, Grotte de } \\
\text { Bazaribe, } 3.6 \text { km SE Menagisy }\end{array}$ & C & 49.47352 & -12.7121 & January 2004 & Female & 90 \\
\hline FMNH 178815 & $\begin{array}{l}\text { Antsiranana/RS d'Analamerana, Grotte de } \\
\text { Bazaribe, } 3.6 \text { km SE Menagisy }\end{array}$ & C & 49.47352 & -12.7121 & January 2004 & Female & 90 \\
\hline FMNH 183932 & $\begin{array}{l}\text { Toliara/PN de Tsimanampetsotsa, } 6.5 \mathrm{~km} \\
\text { NE Efoetse, near Mitoho Cave }\end{array}$ & B & 43.75 & -24.05 & October 2004 & Female & 50 \\
\hline FMNH 183934 & $\begin{array}{l}\text { Toliara/PN de Tsimanampetsotsa, } 6.5 \mathrm{~km} \\
\text { NE Efoetse, near Mitoho Cave }\end{array}$ & B & 43.75 & -24.05 & October 2004 & Female & 50 \\
\hline FMNH 184170 & $\begin{array}{l}\text { Toliara/Grotte d'Androimpano, } 4.2 \mathrm{~km} \mathrm{NE} \\
\text { Itampolo (village), on old road to Ejeda }\end{array}$ & B & 43.96328 & -24.6502 & February 2005 & Female & 110 \\
\hline FMNH 184173 & $\begin{array}{l}\text { Toliara/Grotte d'Androimpano, } 4.2 \mathrm{~km} \mathrm{NE} \\
\text { Itampolo (village), on old road to Ejeda }\end{array}$ & A & 43.96328 & -24.6502 & February 2005 & Female & 110 \\
\hline FMNH 184030 & Mahajanga/4.2 km SE Marovaza, in cave & C & 47.30797 & -14.966 & April 2005 & Female & 40 \\
\hline FMNH 183980 & $\begin{array}{l}\text { Antsiranana/Montagne de Français, } \\
\text { Forêt d'Ampitiliantsambo }\end{array}$ & C & 49.38453 & -12.3371 & January 2005 & Female & 210 \\
\hline FMNH 217940 & $\begin{array}{l}\text { Fianarantsoa/PN de l'Isalo, } 10.5 \text { km } \\
\text { SW Ranohira, Hotel Jardin du Roi }\end{array}$ & B & 45.29 & -22.31 & December 2011 & Female & \\
\hline UADBA 32987 & $\begin{array}{l}\text { Antsiranana/PN d'Ankarana, } 2.6 \text { km E Andrafiabe, } \\
\text { in forest near AndrafiabeCave }\end{array}$ & C & 49.05667 & -13.93167 & September 2012 & Female & 50 \\
\hline FMNH 221308 & $\begin{array}{l}\text { Antsiranana/PN d'Ankarana, } 2.6 \text { km E Andrafiabe, } \\
\text { in forest near Andrafiabe Cave }\end{array}$ & B & 49.05667 & -13.93167 & September 2012 & Female & 50 \\
\hline UADBA 32916 & $\begin{array}{l}\text { Mahajanga/Grotte d'Anjohibe, } 3.7 \text { km } \\
\text { NE Antanamarina }\end{array}$ & B & 46.88598 & -15.53815 & September 2012 & Female & 100 \\
\hline
\end{tabular}

All listed specimens were included in the molecular analyses. and with the exception of those underlined, were also included in the morphometric craniodental analysis. For voucher specimens used in molecular analyses, clade assignments are given based on the supermatrix data presented in Fig. 2. Localities correspond with those presented in Fig. 1. Institutional acronyms are as follows: UADBA: Université d'Antananarivo, Département de Biologie Animale, Antananarivo; FMNH: Field Museum of Natural History, Chicago. Site acronyms: PN Parc National, RNI Réserve Naturelle Intégrale, RS Réserve Spéciale, SF Station Forestière 


\section{Additional files}

Additional file 1: Figures S1 to S4. Single-gene trees. Maximum likelihood tree inferred from CR (S1), Cyt b (S2), bSTAT (S3) and OSTA5 (S4). Posterior probability values and maximum likelihood bootstrap support (in that order) are shown at the nodes. S1) Maximum likelihood tree inferred from mtDNA control region data. Bayesian posterior probability values and maximum likelihood bootstrap support (in that order) are shown at the nodes. S2) Maximum likelihood tree inferred from mtDNA Cyt $b$ data. Posterior probability values and maximum likelihood bootstrap support (in that order) are shown at the nodes. S3) Maximum likelihood tree inferred from nuclear intron bSTAT. Posterior probability values and maximum likelihood bootstrap support (in that order) are shown at the nodes. S4) Maximum likelihood tree inferred from the nuclear intron OSTA5. Posterior probability values and maximum likelihood bootstrap support (in that order) are shown at the nodes. (DOC $21377 \mathrm{~kb}$ )

Additional file 2: Figure S5. Alternative maximum clade probability tree, inferred from the analysis of Cyt $b$ data. A strict molecular clock model with a fixed mean substitution rate of $1.30 \times 10^{-8}$ subs/site/year was performed. Values at nodes indicate the posterior mean substitution rate (subs/site/year). Shaded bars indicate the 95\% highest posterior density (HPD) credibility intervals. (DOC $118 \mathrm{~kb}$ )

\section{Competing interests}

The authors declare that they have no competing interests.

\section{Authors' contributions}

AJ, SWM, MCS and SMG designed the study; AJ and SWM conducted laboratory work; AJ, SWM, MCS, SMG analyzed the data; AJ, SWM, MCS, JML, and SMG wrote the manuscript. All authors read and approved the final manuscript.

\section{Acknowledgments}

We are grateful to Madagascar National Parks and the Ministère des Forêts et de l'Environnement, Direction Générale des Forêts, Direction de la Conservation de la Biodiversité et du Système des Aires Protégées for providing authorization for the capture, collection and exportation of animals under a protocol of collaboration between the Département de Biologie Animale of the Université d'Antananarivo, Association Vahatra and the Field Museum of Natural History. Funding was provided to A. R. R. by the IDP Foundation, Inc., associated with the Field Museum of Natural History African Training Fund, as well as the College of Agriculture, Engineering and Science, School of Life Sciences, University of KwaZulu-Natal. Different field projects over the years on Madagascar resulted in the collection of Hipposideros samples used in this study and generously supported by the John D. and Catherine T. MacArthur Foundation and the Volkswagen Foundation. For providing tissues of Hipposideros from Tanzania, we are grateful to William Stanley and for access to tissue samples, we acknowledge John Phelps (FMNH) and Julie Feinstein $(\mathrm{AMNH})$. For assistance in the field, we are grateful to Erwan Lagadec, Tsibara Mbohoahy, Claude F. Rakotondramanana, Beza Ramasindrazana, Julie Ranivo and Peter Taylor. For comments on an earlier version of this manuscript, we acknowledge the help of Andrey Puzachenko, Miguel Vences, and an anonymous reviewer.

\footnotetext{
Author details

${ }^{1}$ School of Life Sciences, Pietermaritzburg Campus, Rabie Saunders Building, University of Kwa-Zulu Natal, Pietermaritzburg 3209, South Africa.

${ }^{2}$ Association Vahatra, BP 3972, Antananarivo 101, Madagascar. ${ }^{3}$ School of Life Sciences, Biological Sciences Building, South Ring Road, Westville Campus, University of Kwa-Zulu Natal, Westville 3630, South Africa. ${ }^{4}$ Field Museum of Natural History, 1400 South Lake Shore Drive, Chicago, IL 60605, USA. ${ }^{5}$ Department of Genetics, University of KwaZulu-Natal, Pietermaritzburg Campus, Rabie Saunders Building, Rm 36, Pietermaritzburg 3209, South Africa.
}

Received: 25 March 2015 Accepted: 12 October 2015

Published online: 30 October 2015

\section{References}

1. Simmons NB. Order Chiroptera. In: Wilson DE, Reeder DM, editors. Mammal species of the World: a taxonomic and geographic reference. 3rd ed. Baltimore: Johns Hopkins University Press; 2005. p. 312-529.

2. Bates PJJ, Rossiter SJ, Suyanto A, Kingston T. A new species of Hipposideros (Chiroptera: Hipposideridae) from Sulawesi. Acta Chiropterologica. 2007;9(1):13-26.

3. Douangboubpha B, Bumrungsri S, Satasook C, Soisook P, Si Si Hla B, Aul B, et al. A new species of small Hipposideros (Chiroptera: Hipposideridae) from Myanmar and a revaluation of the taxon $\mathrm{H}$. nicobarulae Miller, 1902 from the Nicobar Islands. Acta Chiropterologica. 2011;13(1):61-78.

4. Guillén-Servent A, Francis CM. A new species of bat of the Hipposideros bicolor group (Chiroptera: Hipposideridae) from Central Laos, with evidence of convergent evolution with Sundaic taxa. Acta Chiropterologica. 2006;8:39-61.

5. Thong VD, Puechmaille SJ, Denzinger A, Bates PJJ, Dietz C, Csorba G, et al. Systematics of the Hipposideros turpis complex and a description of a new subspecies from Vietnam. Mamm Rev. 2012:42:166-92.

6. Koopman KF. Chiroptera: Systematics. In: Niethammer J, Schliemann H, Starck D, editors. Handbuch der Zoologie, vol. VII. Berlin: Walter de Gruyter; 1994. p. 100-9.

7. McWilliam AN. Adaptive responses to seasonality in four species of insectivorous bats in coastal Kenya. University of Aberdeen: PhD thesis; 1982.

8. Peterson RL, Eger JL, Mitchell L. Chiroptères. Faune de Madagascar. 1995;84:1-204.

9. Pye JD. Bimodal distribution of constant frequencies in some hipposiderid bats (Mammalia: Hipposideridae). J Zool. 1972;166:325-35.

10. Murray SW, Campbell P, Kingston T, Zubaid A, Francis CM, Kunz TH. Molecular phylogeny of hipposiderid bats from Southeast Asia and evidence of cryptic diversity. Mol Phylogenet Evol. 2012;62:597-611.

11. Goodman SM, Ramasindrazana B. Bats or the order Chiroptera. In: Goodman SM, Raherilalao MJ, editors. Atlas of selected land vertebrates of Madagascar. Antananarivo: Association Vahatra; 2013. p. 169-209.

12. Kofoky A, Andriafidison D, Ratrimomanarivo F, Razafimanahaka HJ, Rakotondravony D, Racey PA, et al. Habitat use, roost selection and conservation of bats in Tsingy de Bemaraha National Park, Madagascar. Biodivers Conserv. 2007;16(4):1039-53.

13. Rakotoarivelo AR, Ranaivoson N, Ramilijaona OR, Kofoky AF, Racey PA, Jenkins RKB. Seasonal food habits of five sympatric forest microchiropterans in western Madagascar. J Mamm. 2007:88:959-66.

14. Rakotoarivelo AR, Ralisata M, Ramilijaona OR, Rakotomalala MR, Racey PA, Jenkins RKB. The food habits of a Malagasy giant: Hipposideros commersoni (E. Geoffroy, 1813). Afr J Ecol. 2009;47(3):283-8.

15. Razakarivony VR, Rajemison B, Goodman SM. The diet of Malagasy Microchiroptera based on stomach contents. Mamm Biol. 2005;70(5):312-6.

16. Ranivo J, Goodman SM. Variation géographique de Hipposideros commersoni de la zone sèche de Madagascar (Mammalia, Chiroptera, Hipposideridae). Verhandlungen des naturwissenschaftlichen Vereins Hamburg. 2007;43:35-56.

17. Monadjem A, Taylor PJ, Cotterill FPD, Schoeman MC. Bats of southern and central Africa: a biogeographic and taxonomic synthesis. Johannesburg: University of the Witwatersrand; 2010.

18. Irwin DM, Kocher TD, Wilson AC. Evolution of the cytochrome $b$ gene of mammals. J Mol Evol. 1991;32:128-44.

19. Wilkinson GS, Chapman AM. Length and sequence variation in evening bat d-loop mtDNA. Genetics. 1991;128:607-17.

20. Eick GN, Jacobs DS, Matthee CA. A nuclear DNA phylogenetic perspective on the evolution of echolocation and historical biogeography of extant bats (Chiroptera). Mol Biol Evol. 2005;22:1869-86.

21. Matthee CA, Burzlaft JD, Taylor JF, Davis SK. Mining the mammalian genome for artiodactyl systematics. Syst Biol. 2001;50:367-90.

22. Igea J, Juste J, Castresana J. Novel intron markers to study the phylogeny of closely related mammalian species. BMC Evol Biol. 2010;10:369.

23. Thompson JD, Gibson TJ, Plewniak F, Jeanmougin F, Higgins DG. The CLUSTAL_X windows interface: flexible strategies for multiple sequence alignment aided by quality analysis tools. Nucleic Acids Res. 1997;25(24):4876-82

24. Hall TA. BioEdit: a user-friendly biological sequence alignment editor and analysis program for Windows 95/98/NT. Nucleic Acids Symp Ser. 1999;41:95-8.

25. Tamura K, Stecher G, Peterson D, Filipski A, Kumar S. MEGA6: Molecular Evolutionary Genetics Analysis version 6.0. Mol Biol Evol. 2013;30:2725-9. 
26. Zwickl DJ. Genetic algorithm approaches for the phylogenetic analysis of large biological sequence datasets under the maximum likelihood criterion. Ph.D. dissertation: The University of Texas; 2006.

27. Ronquist F, Teslenko M, Van der Mark P, Ayres D, Darling A, Höhna S, et al. MrBayes 3.2: efficient Bayesian phylogenetic inference and model choice across a large model space. Syst Biol. 2012;61:539-42.

28. Darriba D, Taboada GL, Doallo R, Posada D. jModelTest 2: more models, new heuristics and parallel computing. Nat Methods. 2012;9(8):772.

29. Posada D, Crandall KA. Modeltest: testing the model of DNA substitution. Bioinformatics. 1998;14:817-8.

30. Rambaut A, Suchard MA, Xie D, Drummond AJ. Tracer v1.6; 2014. http://beast.bio.ed.ac.uk/Tracer (accessed October 2014).

31. Felsenstein J. PHYLIP (Phylogeny Inference Package). Distributed by the author. Seattle, WA: Department of Genome Sciences, University of Washington; 2005.

32. McKenna MC, Bell SK. Classification of mammals above the species level. New York: Columbia University Press; 1997.

33. Simmons NB, Geisler JH. Phylogenetic relationships of Icaronycteris, Archaeonyteris, Hassianycteris and Palaeochiropteryx to extant bat lineages, with comments on the evolution of echolocation and foraging strategies in Microchiroptera. Bull Amer Mus Nat Hist. 1998;235:1-182.

34. Sigé B. Le gisement du Bretou (Phosphorites de Quercy, Tarn-et-Garonne, France) et sa faune de Vertèbres de l'Éocène supérieur. Palaeontographica. 1988;205:69-102.

35. Foley NM, Thong VD, Soisook P, Goodman SM, Armstrong KN, Jacobs DS, et al. How and why overcome the impediments to resolution: lessons from rhinolophid and hipposiderid bats. Mol Biol Evol. 2015;32:313-33.

36. Koubínová D, Sreepada KS, Koubek P, Zima J. Karyotypic variation in rhinolophid and hipposiderid bats (Chiroptera: Rhinolophidae, Hipposideridae). Acta Chiropterologica. 2010;12(2):393-400.

37. Taylor PJ, Stoffberg S, Monadjem A, Schoeman MC, Bayliss J, Cotterill FPD. Four new bat species (Rhinolophus hildebrandtii complex) reflect PlioPleistocene divergence of dwarfs and giants across an Afromontane archipelago. PLoS ONE. 2012;7(9), e41744.

38. Teeling EC, Springer MS, Madsen O, Bates P, O'Brien SJ, Murphy WJ. A molecular phylogeny for bats Illuminates biogeography and the fossil record. Science. 2005;307:580-4.

39. Drummond AJ, Ho SYW, Phillips MJ, Rambaut A. Relaxed phylogenetics and dating with confidence. PLoS Biol. 2006;4, e88.

40. Drummond AJ, Rambaut A. BEAST: Bayesian evolutionary analysis by sampling trees. BMC Evol Biol. 2007:7:214.

41. Nabholz B, Glemin S, Galtier N. Strong variations of mitochondrial mutation rate across mammals - the longevity hypothesis. Mol Biol Evol. 2008;25:120-30.

42. Rambaut A: FigTree; 2009. http://tree.bio.ed.ac.uk/software/figtree/ (accessed January 2012).

43. Freeman PW. A multivariate study of the family Molossidae (Mammalia, Chiroptera): morphology, ecology, evolution. Fieldiana: Zoology, new series. 1981;7:1-171.

44. Ramasindrazana B, Rakotondramanana CF, Schoeman MC, Goodman SM. Evidence of echolocation call divergence in Hipposideros commersoni sensu stricto (E. Geoffroy, 1803) from Madagascar and correlation with body size. Acta Chiropterologica. 2015;17(1):85-94.

45. Anderberg MR. Cluster analysis for applications. New York: Academic; 1973.

46. Davis JC. Statistics and data analysis in geology. New York: John Wiley and Sons; 1973.

47. Taylor PJ, Kearney TC, Peterhans JCK, Baxter RM, Willows-Munro S. Cryptic diversity in forest shrews of the genus Myosorex from southern Africa, with the description of a new species and comments on Myosorex tenuis. Zool J Linnean Soc. 2013;169:881-902.

48 Esselstyn JA, Evans BJ, Sedlock JL, Anwarali Kahn FA, Heaney LR. Singlelocus species delimitation: a test of the mixed yule-coalescent model, with an empirical application to Philippine round-leaf bats. Proc R Soc B: Biol Sci. 2012;279:3678-86

49. Lavery TH, Leung LK-P, Seddon JM. Molecular phylogeny of hipposiderid bats (Chiroptera: Hipposideridae) from Solomon Islands and Cape York Peninsula, Australia. Zoologica Scripta. 2014;43:429-42.

50. Vallo P, Guillén-Servent A, Benda P, Pires BD, Koubek P. Variation of mitochondrial DNA in the Hipposideros caffer complex (Chiroptera: Hipposideridae) and its taxonomic implications. Acta Chiropterologica. 2008;10:193-206.
51. Vallo P, Benda P, Martínková N, Kaňuch P, Kalko EKV, Červený J, et al. Morphologically uniform bats Hipposideros aff. ruber (Hipposideridae) exhibit high mitochondrial genetic diversity in southeastern Senegal. Acta Chiropterologica. 2011;13:79-88.

52. Thabah A, Rossiter SJ, Kingston T, Zhang S, Parsons S, Mya KM, et al. Genetic divergence and echolocation call frequency in cryptic species of Hipposideros larvatus s.l. (Chiroptera: Hipposideridae) from the Indo-Malayan region. Biol J Linn Soc. 2006;88:119-30.

53. Avise JC. Molecular markers, natural history, and evolution. 2nd ed Massachusetts: Sinauer Associates; 2004.

54. Baker RJ, Bradley RD. Speciation in mammals and the genetic species concept. J Mamm. 2006;87:643-62.

55. Kingston T, Lara MC, Jones G, Akbar Z, Kunz TH, Schneider CJ. Acoustic divergence in two cryptic Hipposideros species: a role for social selection? Proc R Soc Lond. 2001:268:1381-6.

56. Burney DA. Climate change and fire ecology as factors in the Quaternary biogeography of Madagascar. In: Lourenço WR, editor. Biogéographie de Madagascar. Paris: Editions ORSTOM; 1995. p. 49-58.

57. Straka H. Histoire de la végétation de Madagascar oriental dans les dernières 100 millénaires. In: Lourenço WR, editor. Biogéographie de Madagascar. Paris: Editions ORSTOM; 1995. p. 75-89.

58. Wilmé L, Goodman SM, Ganzhorn JU. Biogeographic evolution of Madagascar's microendemic biota. Science. 2006;312:1063-5.

59. Vences M, Wollenberg KC, Vieites DR, Lees DC. Madagascar as a mode region of species diversification. Trends Ecol Evol. 2009;24:456-65.

60. Goodman SM, Jungers WL. Extinct Madagascar: picturing the island's past. Chicago: The University of Chicago Press; 2014.

61. Sabatier $\mathrm{M}$, Legendre $\mathrm{S}$. Une faune à rongeurs et chiroptères Plio-Pléistocènes de Madagascar. Actes du 100e Congrès National des Sociétés Savantes, Montpellier, Section des Sciences. 1985;6:21-8.

62. Samonds KE. Late Pleistocene bat fossils from Anjohibe Cave, northwestern Madagascar. Acta Chiropterologica. 2007;9:39-65.

63. Russell AL, Ranivo J, Palkovacs EP, Goodman SM, Yoder AD. Working at the interface of phylogenetics and population genetics: a biogeographical analysis of Triaenops spp. (Chiroptera: Hipposideridae). Mol Ecol. 2007;16:839-51.

64. Ratrimomanarivo FH, Goodman SM, Stanley WT, Naidoo T, Taylor PJ, Lamb J. Geographic and phylogeographic variation in Chaerephon leucogaster (Chiroptera: Molossidae) of Madagascar and the western Indian Ocean islands of Mayotte and Pemba. Acta Chiropterologica. 2009;11:25-52.

65. Weyeneth N, Goodman SM, Ruedi M. Do diversification models of Madagascar's biota explain the population structure of the endemic bat Myotis goudoti (Chiroptera: Vespertilionidae)? J Biogeog. 2010;38:44-54.

66. Vaughan TA. Foraging behaviour of the giant leaf-nosed bat (Hipposideros commersoni). East Afr Wildlife J. 1977;15:237-49.

67. Norberg UM, Rayner JMV. Ecological morphology and flight in bats (Mammalia: Chiroptera): wing adaptations, flight performance, foraging strategy and echolocation. Philos Trans R Soc Lond B Biol Sci. 1987;316:335-427

68. Bernard E, Fenton MB. Bat mobility and roosts in a fragmented landscape in Central Amazonia, Brazil. Biotropica. 2003;35:262-77.

69. Jones G, Rayner MV. Optimal flight speed in pipistrelle bats, Pipistrellus pipistrellus. In: Hanák V, Horáček I, Geisler J, editors. European bat research 1987. Prague: Charles University Press; 1989. p. 247-53.

\section{Submit your next manuscript to BioMed Central and take full advantage of:}

- Convenient online submission

- Thorough peer review

- No space constraints or color figure charges

- Immediate publication on acceptance

- Inclusion in PubMed, CAS, Scopus and Google Scholar

- Research which is freely available for redistribution 